\title{
Bickerstaff brainstem encephalitis with or without anti-GQ1b antibody
}

Keisuke Yoshikawa, MD, PhD, Motoi Kuwahara, MD, PhD, Miyuki Morikawa, MD, PhD, and Susumu Kusunoki, MD, PhD

Neurol Neuroimmunol Neuroinflamm 2020;7:e889. doi:10.1212/NXI.0000000000000889

\section{Abstract}

\section{Objective}

To clarify the differences in clinical characteristics between anti-GQ1b antibody-positive and antibody-negative Bickerstaff brainstem encephalitis (BBE).

\section{Methods}

We compared 73 anti-GQ1b antibody-positive BBE cases with 10 antibody-negative cases. Their clinical information and sera were collected from various hospitals throughout Japan between 2014 and 2017. The anti-GQ1b antibody was examined in each serum sample by ELISA.

\section{Results}

We identified the distinctive findings of anti-GQ1b antibody-positive BBE compared with the antibody-negative cases: (1) upper respiratory infection and sensory disturbance were more common, (2) the cell count or protein concentration was lower in the CSF, (3) the abnormal findings on brain MRI were less, and (4) the consciousness disturbance disappeared earlier. Furthermore, IV immunoglobulin (IVIG) was more frequently administered to the anti-GQ1b antibody-positive cases of BBE compared with the antibody-negative cases.

\section{Conclusions}

BBE with anti-GQ1b antibody has homogeneous features. IVIG is the treatment used prevalently for BBE with anti-GQ1b antibody in Japan.
Correspondence

Dr. Kusunoki

kusunoki-tky@umin.ac.jp 


\section{Glossary}

BBB = blood-brain barrier; BBE = Bickerstaff brainstem encephalitis; FG = functional grade; FS = Fisher syndrome; IVIG = IV immunoglobulin; $\mathbf{M M P}=$ matrix metalloproteinase; $\mathbf{N C S}=$ nerve conduction study; $\mathbf{P P}=$ plasmapheresis; $\mathbf{T B S}=$ Tris-buffered saline.

Bickerstaff brainstem encephalitis (BBE) is an immunologic disease characterized by the acute onset of external ophthalmoplegia, ataxia, and consciousness disturbance, mostly subsequent to infection. BBE is considered to be a variant of Fisher syndrome (FS), which also exhibits external ophthalmoplegia and ataxia. The IgG anti-GQ1b antibody is frequently present in the acute phase sera of patients with BBE, and in FS. However, few clinical studies of a large number of patients with BBE have been reported because it is a rare disease. Recently, Koga et al. ${ }^{1}$ conducted a nationwide survey of the Japanese population and reported the epidemiologic features and nosological position of $\mathrm{BBE}$ among brainstem encephalitis. Furthermore, they proposed the criteria for the diagnosis of $\mathrm{BBE}$, in which $\mathrm{BBE}$ was divided into 2 categories (i.e., definite and probable) and suggested that definite $\mathrm{BBE}$, which is defined as having typical clinical features and positive anti-GQ1b antibody, showed rather homogeneous characteristics compared with probable BBE. In this study, we focused on patients with antiGQ1b antibody-positive BBE, either definite or probable, and compared them with patients with antibody-negative $\mathrm{BBE}$ to clarify the clinical significance of the anti-GQ1b antibody in BBE.

\section{Methods}

\section{Patients and serum samples}

A total of 641 serum samples from patients diagnosed with either BBE or suspected BBE were sent to our laboratory from various hospitals throughout Japan for testing for antiglycolipid antibodies between 2014 and 2017. We excluded 481 cases from the present study because the clinical findings apparently did not fulfill the criteria for BBE. To evaluate the details of the remaining 160 cases (53 suspected of definite $\mathrm{BBE}$ and 107 suspected of probable BBE), we sent the questionnaires to the attending physicians. Finally, we received responses for 112 cases, which comprised 83 cases of BBE (50 with definite BBE and 33 with probable BBE) diagnosed based on the proposed criteria ${ }^{1}$ and 29 cases with other diseases, including infectious meningoencephalitis, malignant lymphoma, anti-Ma2-associated encephalitis, neuro-Sweet disease, and acute disseminated encephalomyelitis. Finally, the 83 patients with BBE were enrolled in the study. We identified patients who met the following criteria as having BBE. ${ }^{1}$ Definite BBE was defined by typical clinical features (presence of the neurologic triad and an acute selflimited clinical course) and positivity for the IgG anti-GQ1b antibody. By contrast, probable BBE was defined by atypical clinical features (unevaluated ataxia because of severe limb weakness or consciousness disturbance, unconfirmed recovery of the symptoms, laterality of the ophthalmoplegia, or long tract sign instead of consciousness disturbance) $)^{1}$ and positivity for the IgG anti-GQ1b antibody or typical clinical features and negativity for the IgG anti-GQ1b antibody.

\section{Antibody testing (ELISA and combinatorial glycoarray)}

IgG antibodies against GQ1b were investigated by ELISA, as described previously. ${ }^{2}$ Moreover, anti-GQ1b-negative samples on conventional ELISA were examined by ELISA using tris-buffered saline (TBS) with added $\mathrm{Ca}^{2+}$ cations and combinatorial glycoarray ${ }^{3-6}$ to detect $\mathrm{Ca}^{2+}$-dependent antibodies and antiglycolipid complex antibodies.

\section{Statistical analysis}

The differences in proportions were examined by the $\chi^{2}$ test or Fisher exact probability, and the differences in the median values were assessed using the Mann-Whitney $U$ test. A 2-tailed $p$ value $<0.05$ was considered significant. All analyses were performed using the SPSS software (IBM Corp., Armonk, NY).

\section{Study approval and patient consents}

This study was approved by the Internal Review Board of Kindai University Faculty of Medicine. All participants provided written informed consent.

\section{Data availability}

Anonymized data not published within the article will be shared by request from any qualified investigator.

\section{Results}

\section{Study profile}

Of the 33 cases with probable BBE, 22 were positive for the anti-GQ1b antibody by conventional ELISA. The remaining 11 cases were tested by ELISA using TBS with added $\mathrm{Ca}^{2+}$ cations and combinatorial glycoarray. Because only one of these cases was positive in either method, the number of anti-GQ1b antibody-positive cases with probable BBE was 23 (23 of 33, $70 \%)$. In total, the positive ratio of anti-GQ1b antibody in BBE was $88 \%$ ( 73 of 83 ). We compared the characteristics of 73 anti-GQ1b antibody-positive BBE cases (50 definite and 23 probable) with those of 10 antibody-negative cases (figure 1).

\section{Comparison of patient characteristics}

The proportion of patients who presented ophthalmoplegia, ataxia, and consciousness disturbance was not different between the 2 groups because most patients with the anti-GQ1b antibody and all the patients without the anti-GQ1b antibody exhibited the triad, according to the diagnostic criteria. However, the proportion of patients with antecedent 
Figure 1 Study profile

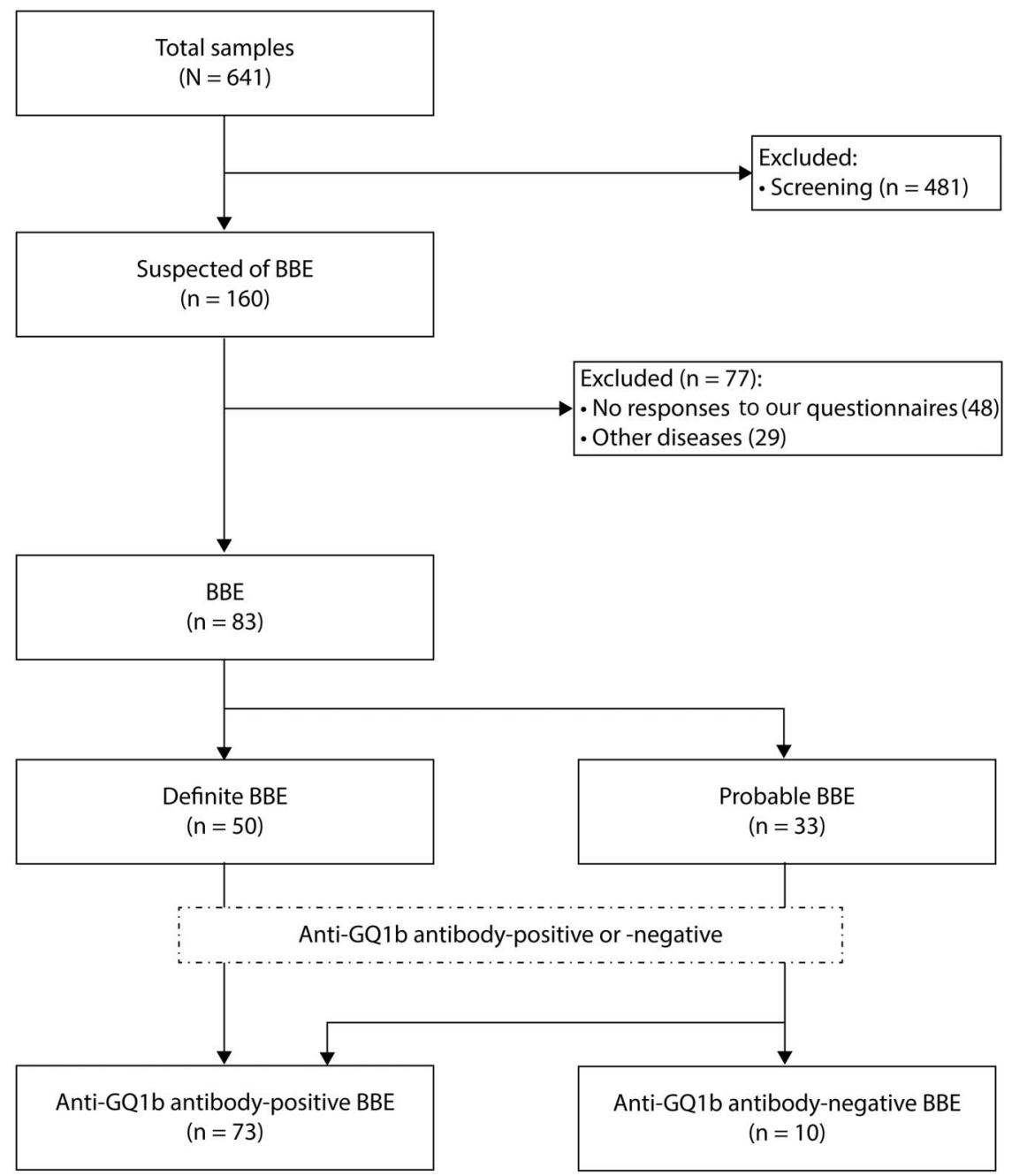

$\mathrm{BBE}=$ Bickerstaff brainstem encephalitis.

respiratory infection and sensory disturbance was higher in the anti-GQ1b antibody-positive group than it was in the antibody-negative group $(p<0.01$, respectively). The presence of muscle weakness, pyramidal signs, autonomic dysfunction, and need for mechanical ventilation was not different between the 2 groups (table 1 ).

Patients with BBE without the anti-GQ1b antibody showed significantly higher cell count and protein levels in the CSF than did those with the anti-GQ1b antibody. Abnormal findings in the brain MRI were more frequently observed in patients without the anti-GQ1b antibody. Brain MRI in those patients revealed such findings as high-intensity abnormalities on $\mathrm{T}_{2}$-weighted images or fluid attenuated inversion recovery in the midbrain or medulla oblongata $(\mathrm{n}=2)$, in the corpus callosum $(\mathrm{n}=1)$, around the ventricle $(n=1)$, or in the temporal pole $(n=1)$, whereas patients with BBE with the anti-GQ1b antibody showed the abnormalities in the deep white matter $(n=3)$, in the left thalamus $(\mathrm{n}=1)$, or in the bilateral pyramidal tracts $(\mathrm{n}=1)$. The remaining one was not referred in the questionnaire (table 2).
A nerve conduction study (NCS) was performed in 55 patients with BBE with the anti-GQ1b antibody and in 6 patients without the anti-GQ1b antibody. The results showed that "unclassified" was common and "acute inflammatory demyelinating polyneuropathy" or "acute motor axonal neuropathy" were very uncommon according to the criteria by Ho. The 2 groups exhibited no significant differences in electrodiagnosis (data not shown).

\section{Comparison between probable BBE with and without the anti-GQ1b antibody}

In this study, probable BBE comprised antibody-positive and antibody-negative patients. The differences between probable BBE with and without the anti-GQ1b antibody are shown in table 3. Similar to the results reported above for the whole cohort of BBE, the proportion of patients who had antecedent respiratory infection was higher among anti-GQ1b antibodypositive cases compared with antibody-negative cases $(p=$ $0.02)$. Moreover, patients with probable BBE without the antiGQ1b antibody exhibited higher cell count and protein levels in 
Table 1 Clinical features of patients with Bickerstaff brainstem encephalitis

\begin{tabular}{|c|c|c|c|}
\hline & Anti-GQ1b antibody-positive $(n=73)$ & Anti-GQ1b antibody-negative $(n=10)$ & $p$ Value \\
\hline Age (Median [range]) & $40[15-80]$ & 50 [19-84] & n.s. \\
\hline Sex (male/female) & $43 / 30$ & $5 / 5$ & n.s. \\
\hline Preceding infection, $\mathrm{n}(\%)$ & $65(89)$ & $5(50)$ & $<0.01$ \\
\hline Respiratory infection & $51(70)$ & $2(20)$ & $<0.01$ \\
\hline Gastrointestinal infection & $11(15)$ & $0(0)$ & n.s. \\
\hline Ataxia, n (\%) & $68(93)$ & $10(100)$ & n.s. \\
\hline Cerebellar ataxia & $39(53)$ & $6(60)$ & n.s. \\
\hline Sensory ataxia & $9(12)$ & $0(0)$ & n.s. \\
\hline Undeterminable & $20(27)$ & $4(40)$ & n.s. \\
\hline Muscle weakness, n (\%) & $45(62)$ & $6(60)$ & n.s. \\
\hline \multicolumn{4}{|l|}{ Tendon reflex, $\mathrm{n}(\%)$} \\
\hline Brisk & $17(23)$ & $3(30)$ & n.s. \\
\hline Normal & $13(18)$ & $2(20)$ & n.s. \\
\hline Decreased & $14(19)$ & $2(20)$ & n.s. \\
\hline Absent & $29(40)$ & $3(30)$ & n.s. \\
\hline Pathologic reflex, n (\%) & $35(48)$ & $2(20)$ & n.s. \\
\hline Sensory disturbance, $\mathrm{n}(\%)$ & $41(56)$ & $1(10)$ & $<0.01$ \\
\hline Dysesthesia & $32(44)$ & $0(0)$ & $<0.01$ \\
\hline Superficial sense impairment & $8(11)$ & $0(0)$ & n.s. \\
\hline Pain & $2(3)$ & $1(10)$ & n.s. \\
\hline Deep sense impairment & $8(11)$ & $0(0)$ & n.s. \\
\hline Autonomic dysfunction, $n$ (\%) & $26(36)$ & $4(40)$ & n.s. \\
\hline Mechanical ventilation, $\mathbf{n}(\%)$ & $15(21)$ & $2(20)$ & n.s. \\
\hline
\end{tabular}

Abbreviation: n.s. $=$ not significant.

the CSF and more frequent abnormal findings on brain MRI than did the antibody-positive patients $(p<0.01$, respectively).

\section{Comparison between definite and probable BBE in anti-GQ1b antibody-positive BBE}

To confirm the homogeneity of anti-GQ1b antibody-positive BBE, we compared definite cases with probable cases among anti-GQ1b antibody-positive BBE. No differences were found in the proportion of patients who had antecedent respiratory infection, dysesthesia, abnormal CSF findings, or abnormality on brain MRI and also in a median time until the improvement of the consciousness disturbance. The reasons why some patients with anti-GQ1b antibody were categorized into probable BBE were as follows: impossible to evaluate their ataxia because of severe limb weakness or consciousness disturbance in 5 , unconfirmed recovery of the symptoms or remarkable laterality of external ophthalmoplegia in 17, and long tract sign instead of impaired level of consciousness in one.

\section{Treatments and responses}

Overall, most of the patients ( 79 of $83,95 \%$ ) received immunologic treatments, such as IV immunoglobulin (IVIG), corticosteroids, plasmapheresis (PP), or a combination of any of them. Among the remaining 4 patients, 2 recovered spontaneously and no information on treatment was obtained for 2 cases. Acyclovir or vitamin B12 was added at the discretion of the treating neurologists.

The immunologic treatments administered to the 70 patients with the anti-GQ1b antibody were as follows: IVIG alone in 25, corticosteroids alone in $8, \mathrm{PP}$ alone in 1 , combination of IVIG and corticosteroids in 33, and combination of IVIG, corticosteroids, and PP in 3 patients. The 9 patients without the antiGQ1b antibody were treated as follows: IVIG alone in 3, corticosteroids alone in 4 , combination of IVIG and corticosteroids in 1 , and combination of IVIG, corticosteroids, and PP in 1 patient. Among patients for whom treatment information was available, 
Table 2 CSF and radiologic findings in patients with Bickerstaff brainstem encephalitis

\begin{tabular}{|c|c|c|c|}
\hline & Anti-GQ1b antibody-positive $(n=73)$ & Anti-GQ1b antibody-negative $(n=10)$ & $p$ Value \\
\hline Duration (d), median [range] & $3[1-23]$ & $5.5[1-22]$ & n.s. \\
\hline Pleocytosis (>5/ $\mu \mathrm{L}), \mathrm{n}(\%)$ & $34 / 71(48)$ & $6 / 9(67)$ & n.s. \\
\hline Median [range] & $12.5[5.3-90]$ & $75.9[11-251]$ & $<0.01$ \\
\hline Elevated protein ( $\geq 45 \mathrm{mg} / \mathrm{dL}), \mathrm{n}(\%)$ & $20 / 71(28)$ & $8 / 9(89)$ & $<0.01$ \\
\hline Median [range] & $63.5[47-132]$ & 159 [59-381] & $<0.01$ \\
\hline Brain MRI abnormal findings, $\mathbf{n}(\%)$ & 6/73 (8) & $5 / 10(50)$ & $<0.01$ \\
\hline
\end{tabular}

Abbreviation: n.s. = not significant .

Duration, days from onset to conduct of lumbar puncture.

anti-GQ1b antibody-positive cases received IVIG more frequently than did antibody-negative patients ( $86 \%$ [61 of 71] vs $50 \%$ [5 of 10], $\mathrm{p}=0.021$ ).

We defined it as a favorable response, when each treatment improved the functional grade (FG) by one or more points and FG reaches no more than 2 at the final visit. ${ }^{8,9}$ The proportion of favorable responses to representative treatments were $80 \%$ (20 of 25 ) in IVIG alone, $75 \%$ (6 of 8) in corticosteroids alone, and $91 \%$ (30 of 33) in IVIG added with corticosteroids in patients with anti-GQ1b antibody, whereas those were 100\% (3 of 3), $75 \%$ (3 of 4 ) and 100\% (1 of 1), respectively, in those without anti-GQ1b antibody. There were no differences in response rate in these treatments between the 2 groups.

\section{Severity and prognosis}

The disease severity was not significantly different between antiGQ1b antibody-positive and anti-GQ1b antibody-negative cases. The median of the FG at the nadir was 4 (bedridden or chairbound) and those at the final visit were 1 in both groups. The median time to the nadir was 4 days in antibody-positive cases and
6 days in antibody-negative cases. We focused on the time required for improvement of the symptom triad. Although no significant difference was found between the groups regarding ophthalmoplegia and ataxia, the consciousness disturbance disappeared earlier in the anti-GQ1b antibody-positive cases than in the antibody-negative cases (10 days vs 23 days, $p=0.014$ ) (figure 2 ).

\section{Discussion}

This study was designed to investigate the clinical differences between anti-GQ1b antibody-positive and anti-GQ1b-negative BBE. Overall, we found that anti-GQ1b antibody-positive BBE exhibited distinctive findings. In the antibody-positive group, preceding upper respiratory infection and sensory disturbance were more common, cell count or protein concentration in the CSF were lower, and abnormal findings on brain MRI were rarer compared with the antibody-negative group. Therefore, the patients with anti-GQ1b antibody-positive BBE included in this study had clinical features that were similar to those of the patients with definite BBE reported previously (who all had the anti-GQ1b antibody according to the diagnostic criteria). ${ }^{1}$

Table 3 Comparison between probable BBE with and without the anti-GQ1b antibody

\begin{tabular}{|c|c|c|c|}
\hline & $\begin{array}{l}\text { Probable BBE with the anti-GQ1b antibody } \\
(n=23)\end{array}$ & $\begin{array}{l}\text { Probable BBE without the anti-GQ1b antibody } \\
(n=10)\end{array}$ & $p$ Value \\
\hline Preceding infection, $\mathbf{n}(\%)$ & $21(91)$ & $5(50)$ & 0.02 \\
\hline Respiratory infection & $16(70)$ & $2(20)$ & 0.02 \\
\hline Gastrointestinal infection & $4(17)$ & $0(0)$ & n.s. \\
\hline Dysesthesia, n (\%) & $8 / 23(35)$ & $0(0)$ & n.s. \\
\hline 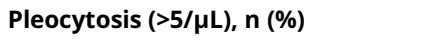 & $8 / 23(35)$ & $6 / 9(67)$ & n.s. \\
\hline Median [range] & $12.5[8-45]$ & $75.9[11-251]$ & 0.01 \\
\hline Elevated protein ( $\geq 45 \mathrm{mg} / \mathrm{dL}), \mathrm{n}(\%)$ & $6 / 23(26)$ & $8 / 9(89)$ & $<0.01$ \\
\hline Median [range] & 68 [48.9-129] & 159 [59-381] & n.s. \\
\hline Brain MRI abnormal findings, $\mathbf{n}(\%)$ & 0/23 (0) & $5 / 10(50)$ & $<0.01$ \\
\hline
\end{tabular}

Abbreviations: $B B E=$ Bickerstaff brainstem encephalitis; n.s. $=$ not significant. 
Figure 2 Median time until the improvement of the symptom triad

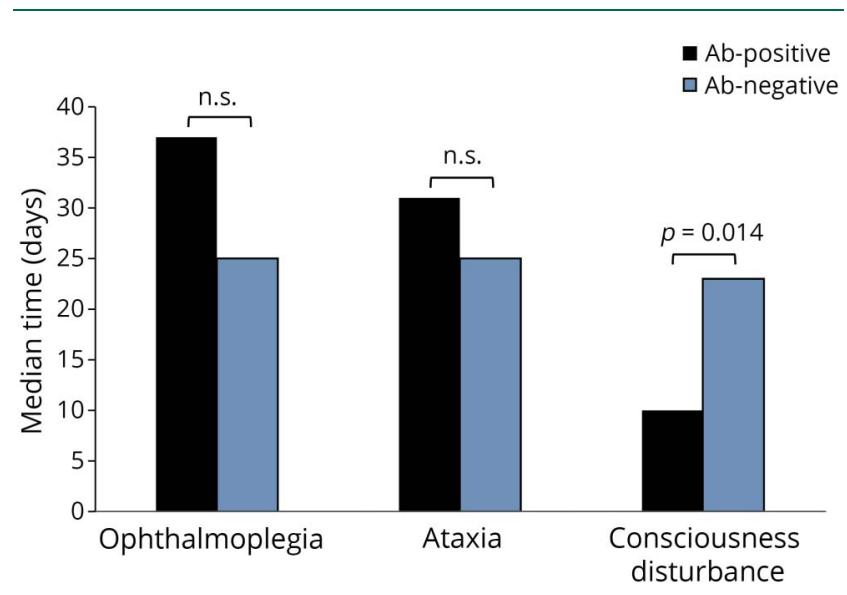

The consciousness disturbance disappeared earlier in patients with the antiGQ1b antibody than it did in those without the antibody $(p=0.014)$. Conversely, there was no significant difference in the median time of ophthalmoplegia and ataxia between the 2 groups. n.s. = not significant.

Moreover, similar clinical features were also found in the antiGQ1b antibody-positive probable BBE. This indicates that the anti-GQ1b antibody may play significant pathogenetic roles in $\mathrm{BBE}$ and determine its clinical characteristics. The treatment modalities and responses did not differ significantly between the 2 groups; however, IVIG alone or IVIG combined with other immunologic treatments were the most prevalent therapies.

The positive ratio of anti-GQ1b antibody was higher than that reported by previous studies. ${ }^{1,10,11}$ Even if they had the typical symptom triad of BBE, some of the patients without the antiGQ1b antibody were not finally diagnosed as having BBE. Thus, we should take into consideration that patients without the anti-GQ1b antibody may be affected by other diseases.

It is noteworthy that dysesthesia was more frequently found in anti-GQ1b antibody-positive BBE. Dysesthesia could be characteristic in this condition and rarely found in the other brainstem encephalitis. Thus, we speculate that the anti-GQ1b antibodies play an important role in the appearance of the dysesthesia. The potential mechanisms of dysesthesia associated with anti-GQ1b antibodies has been supported by previous studies in patients with FS, in which the decreased level of sensory nerve action potential in NCS and the axonal damage in a nerve biopsy was demonstrated. ${ }^{12,13}$

In addition, this was the first study to show that consciousness disturbance exhibited an earlier improvement in anti-GQ1b antibody-positive BBE compared with antibody-negative BBE. The median time to the disappearance of the consciousness disturbance was only 10 days, suggesting that the CNS disturbance observed in anti-GQ1b antibody-positive BBE is mostly functional, rather than organic. By contrast, there was no significant difference in the improvement of ophthalmoplegia and ataxia between antiGQ1b antibody-positive and anti-GQ1b antibody-negative BBE.
Although the mechanism of consciousness disturbance has not been clarified, a previous report has shown that humoral factors, such as matrix metalloproteinase-9 (MMP-9), might be involved in the pathology of BBE. MMP-9, which is secreted by brain microvascular endothelial cells, was significantly increased after exposure to the sera obtained from patients with BBE, whereas it was not changed after exposure to the sera obtained from patients with FS. Moreover, this change of MMP-9 was reversed after the application of MMP inhibitor. ${ }^{14}$ These findings could explain the reason why the blood-brain barrier $(\mathrm{BBB})$ is disturbed and the level of consciousness is decreased in patients with BBE. The spontaneous recovery of consciousness disturbance in anti-GQ1b antibody-positive $\mathrm{BBE}$ might be due to the reversible dysfunction of $\mathrm{BBB}$.

ELISA using TBS with added $\mathrm{Ca}^{2+}$ cations and combinatorial glycoarray detected only one additional case of anti-GQ1b antibody-positive BBE. This may explain the observation that antibody activity in BBE is not enhanced by such techniques, which could be a characteristic finding of anti-GQ1b antibodypositive BBE. Recently, we demonstrated that the positive ratio of the antibody against GQ1b-related antigens increased from $57 \%$ to $73 \%$ in Guillain-Barré syndrome with ophthalmoplegia, whereas no such increase was observed in BBE. ${ }^{15}$

Although a previous study reported that corticosteroids and $\mathrm{PP}$ were mainly administered in $\mathrm{BBE},{ }^{11}$ we found that, recently, IVIG or IVIG combined with corticosteroids were the most prevalent treatments in our cohort. However, we have no evidence of the optimal treatment of BBE, which should be investigated in future studies.

The methods of this study had several limitations. First, the number of patients with $\mathrm{BBE}$ was small because this is a very rare disease. Second, we could not avoid selection biases by attendant physicians. In fact, approximately half of the cases that were suspected of having probable BBE were excluded because of the lack of response to our questionnaires. Third, coexistent other autoantibodies against neuronal surface antigens, such as anti-NMDA receptor antibody, were not examined in all cases. Forth, the clinical information of each patient was retrospectively collected using a questionnaire. Thus, the severity of consciousness disturbance could not be evaluated. In addition, the usage of IVIG in BBE might be due to the preference of the primary physicians in Japan.

In conclusion, our findings indicate that anti-GQ1b antibodypositive BBE has homogeneous features possibly because of the pathogenetic roles of anti-GQ1b antibodies. IVIG alone and IVIG combined with corticosteroids are the most prevalent recent treatments of BBE with anti-GQ1b antibody in Japan. A further prospective research enrolled a larger population is needed to elucidate the pathogenic mechanisms and identify the optimal treatment in BBE.

\section{Acknowledgment}

The authors thank Dr. Susan Halstead and Dr. Hugh Willison for their technical coaching regarding glycoarray. 


\section{Study funding}

Supported by the Ministry of Education, Culture, Sports, Science and Technology of Japan (Grants-in-Aid for Scientific Research, 18H02745) and Health and s Sciences Research Grants on neuroimmunologic diseases.

\section{Disclosure}

None of the authors report any disclosures relevant to the manuscript. Go to Neurology.org/NN for full disclosures.

\section{Publication history}

Received by Neurology: Neuroimmunology \& Neuroinflammation June 16, 2020. Accepted in final form August 18, 2020.

\section{Appendix Authors}

\begin{tabular}{lll}
\hline Name & Location & Contribution \\
\hline $\begin{array}{l}\text { Keisuke } \\
\text { Yoshikawa, PhD }\end{array}$ & $\begin{array}{l}\text { Kindai University } \\
\text { Faculty of Medicine, } \\
\text { Osaka, Japan }\end{array}$ & $\begin{array}{l}\text { Acquisition, analysis and } \\
\text { interpretation of data and } \\
\text { drafted the article }\end{array}$ \\
\hline $\begin{array}{l}\text { Motoi } \\
\text { Kuwahara, } \\
\text { MD, PhD }\end{array}$ & $\begin{array}{l}\text { Kindai University } \\
\text { Faculty of Medicine, }\end{array}$ & $\begin{array}{l}\text { Analyzed and interpreted } \\
\text { data and participated in } \\
\text { drafting the article and } \\
\text { revising it }\end{array}$ \\
\hline $\begin{array}{l}\text { Miyuki } \\
\text { Morikawa, } \\
\text { MD, PhD }\end{array}$ & $\begin{array}{l}\text { Kindai University } \\
\text { Faculty of Medicine, }\end{array}$ & $\begin{array}{l}\text { Acquisition and analysis of } \\
\text { data }\end{array}$ \\
\hline $\begin{array}{l}\text { Osaka, Japan } \\
\text { Kusumoki, } \\
\text { MD, PhD }\end{array}$ & Kindai University & $\begin{array}{l}\text { Subulty of Medicine, } \\
\text { conception and design of the } \\
\text { Study and revised article } \\
\text { critically for important } \\
\text { intellectual content }\end{array}$ \\
& Osaka, Japan &
\end{tabular}

\section{References}

1. Koga M, Kusunoki S, Kaida K, et al. Nationwide survey of patients in Japan with Bickerstaff brainstem encephalitis: epidemiological and clinical characteristics. J Neurol Neurosurg Psychiatry 2012;83:1210-1215.

2. Kusunoki S, Chiba A, Kon $\mathrm{K}$, et al. $\mathrm{N}$-acetylgalactosaminyl GD1a is a target molecule for serum antibody in Guillain-Barre syndrome. Ann Neurol 1994;35: $570-576$.

3. Galban-Horcajo F, Fitzpatrick AM, Hutton AJ, et al. Antibodies to heteromeric glycolipid complexes in multifocal motor neuropathy. Eur J Neurol 2013;20: $62-70$.

4. Rinaldi S, Brennan KM, Kalna G, et al. Antibodies to heteromeric glycolipid complexes in Guillain-Barre syndrome. PLoS One 2013;8:e82337.

5. Morikawa M, Kuwahara M, Ueno R, Samukawa M, Hamada Y, Kusunoki S. Serological study using glycoarray for detecting antibodies to glycolipids and glycolipid complexes in immune-mediated neuropathies. J Neuroimmunol 2016;301: $35-40$.

6. Uchibori A, Gyohda A, Chiba A. Ca(2+)-dependent anti-GQ1b antibody in GQ1bseronegative Fisher syndrome and related disorders. J Neuroimmunol 2016;298: 172-177.

7. Ho TW, Mishu B, Li CY, et al. Guillain-Barre syndrome in northern China: relationship to Campylobacter jejuni infection and anti-glycolipid antibodies. Brain 1995; 118:597-605.

8. Double-blind trial of intravenous methylprednisolone in Guillain-Barre syndrome. Guillain-Barre Syndrome Steroid Trial Group. Lancet 1993;341: $586-590$.

9. Hughes RA, Newsom-Davis JM, Perkin GD, Pierce JM. Controlled trial prednisolone in acute polyneuropathy. Lancet 1978;2:750-753.

10. Ito M, Kuwabara S, Odaka M, et al. Bickerstaff's brainstem encephalitis and Fisher syndrome form a continuous spectrum: clinical analysis of 581 cases. J Neurol 2008; 255:674-682.

11. Odaka M, Yuki N, Yamada M, et al. Bickerstaff's brainstem encephalitis: clinical features of 62 cases and a subgroup associated with Guillain-Barre syndrome. Brain 2003;126:2279-2290.

12. Miller JA, Spyropoulos A, Jaros E, Galban-Horcajo F, Whittaker RG, Willison HJ. Anti-GQ1b ganglioside positive Miller Fisher syndrome-evidence of paranodal pathology on nerve biopsy. J Neuromuscul Dis 2014;1:191-195.

13. Kuwabara S, Asahina M, Nakajima M, et al. Special sensory ataxia in Miller Fisher syndrome detected by postural body sway analysis. Ann Neurol 1999;45: 533-536.

14. Saito K, Shimizu F, Koga M, et al. Blood-brain barrier destruction determines Fisher/ Bickerstaff clinical phenotypes: an in vitro study. J Neurol Neurosurg Psychiatry 2013; 84:756-765.

15. Yoshikawa K, Kuwahara M, Morikawa M, et al. Varied antibody reactivities and clinical relevance in anti-GQ1b antibody-related diseases. Neurol Neuroimmunol Neuroinflamm 2018;5:e501. doi: 10.1212/NXI.0000000000000501. 


\section{Neurology \\ Neuroimmunology \& Neuroinflammation}

Bickerstaff brainstem encephalitis with or without anti-GQ1b antibody

Keisuke Yoshikawa, Motoi Kuwahara, Miyuki Morikawa, et al.

Neurol Neuroimmunol Neuroinflamm 2020;7;

DOI 10.1212/NXI.0000000000000889

This information is current as of September 15, 2020

\section{Updated Information \& Services}

References

Citations

Subspecialty Collections

Permissions \& Licensing

Reprints including high resolution figures, can be found at: http://nn.neurology.org/content/7/6/e889.full.html

This article cites 15 articles, 3 of which you can access for free at: http://nn.neurology.org/content/7/6/e889.full.html\#\#ref-list-1

This article has been cited by 6 HighWire-hosted articles: http://nn.neurology.org/content/7/6/e889.full.html\#\#otherarticles

This article, along with others on similar topics, appears in the following collection(s):

Autoimmune diseases

http://nn.neurology.org//cgi/collection/autoimmune_diseases Guillain-Barre syndrome

http://nn.neurology.org//cgi/collection/guillainbarre_syndrome

Information about reproducing this article in parts (figures,tables) or in its entirety can be found online at:

http://nn.neurology.org/misc/about.xhtml\#permissions

Information about ordering reprints can be found online:

http://nn.neurology.org/misc/addir.xhtml\#reprintsus

Neurol Neuroimmunol Neuroinflamm is an official journal of the American Academy of Neurology.

Published since April 2014, it is an open-access, online-only, continuous publication journal. Copyright

Copyright $\left({ }^{\circ} 2020\right.$ The Author(s). Published by Wolters Kluwer Health, Inc. on behalf of the American

Academy of Neurology.. All rights reserved. Online ISSN: 2332-7812.

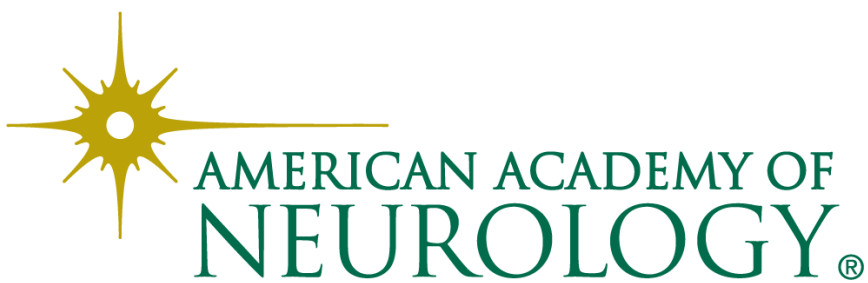

